REVISTA ANDALUZA DE ANTROPOLOGÍA.

NÚMERO 9: LA REPRESENTACIÓN DE LAS CULTURAS EN LA MUSEOLOGÍA ANTROPOLÓGICA DEL ESTADO ESPAÑOL

SEPTIEMBRE DE 2015

ISSN 2174-6796

[pp. 76-104]

http://dx.doi.org/10.12795/RAA.2015.i09.04

Recibido: 31/08/2015

Aceptado: 11/09/2015

\title{
LOS MUSEOS ETNOLÓGICOS EN CATALUÑA. PERSPECTIVAS, RETOS Y DEBATES
}

\author{
Xavier Roigé \\ Universitat de Barcelona
}

\section{Resumen.}

El artículo analiza la situación los museos etnológicos en Cataluña, señalando sus principales tendencias y debates. El autor sostiene que mientras que a nivel general catalán la situación de los museos etnológicos es muy débil (sin haber sido posible crear o consolidar hasta ahora museos etnológicos de carácter nacional o autonómico), por el contrario existe un buen número de pequeños museos etnológicos de carácter comarcal y local, muchos de los cuales tienen un gran interés y dinamismo. Tras una descripción del proceso histórico que han tenido estos museos, se presentan los grandes debates entre los museos locales, los de carácter general y los referidos a otras culturas. El texto acaba indicando los grandes retos que los museos etnológicos deberán afrontar: los efectos de la crisis económica y la disminución de sus presupuestos (que se calcula entre un 30 y un 50\%), la reorganización del mapa de museos locales, los cambios en la noción del patrimonio, la necesidad de creación de un museo nacional de etnología y el acercamiento a los nuevos movimientos sociales y a los temas que preocupan a la sociedad. Sometidos a una fuerte presión por la exigencia de conseguir nuevos recursos, los museos deberán tratar de combinar el valor social y económico del patrimonio.

Palabras clave.

Museos etnológicos, Cataluña, Patrimonio etnológico, Museos locales 


\title{
ETHNOLOGICAL MUSEUMS IN CATALONIA. PERSPECTIVES, CHALLENGES AND DEBATES
}

\begin{abstract}
.
The paper analyses the situation of ethnological museums in Catalonia, noting its main trends and debates. The author argues that in the level of national museums, the situation of Catalan ethnological museums is very weak (not have been possible so far to create or strengthen a national or regional ethnological museum), however there are a number regional and local small ethnological museums, many of which have a vested interest and dynamism. After a description of the historical process that have had these museums, great debates show up among local and national museums and those dealing with other cultures. The paper ends up indicating the great challenges that will face the ethnological museums: the effects of the financial crisis and declining budgets (estimated between 30 and $50 \%$ ), the reorganization of the map of local museums, the changes in the notion of heritage, the need for creating a national museum of ethnology and the approach to the new social movements and issues of concern to society. Under strong pressure from the need to find new resources, museums should try to combine the social and economic value of equity.
\end{abstract}

\section{Keywords.}

Ethnological museums, Catalonia, Ethnological heritage, Local museums

En este artículo se pretende reflexionar sobre la situación de los museos etnológicos en Cataluña, y al mismo tiempo señalar sus principales tendencias y debates. Estos museos tienen características muy distintas, desde museos generales hasta pequeños museos locales, desde museos especializados hasta museos generalistas, desde museos que tratan de la sociedad rural hasta otros que nos hablan de otras culturas, desde algunos que nos ofrecen la imagen de unas sociedades tradicionales hasta otros que abordan los grandes retos de la sociedad contemporánea. Con todo, una rápida mirada a los museos etnológicos de Cataluña en la actualidad nos lleva rápidamente a dos constataciones iniciales. A nivel general catalán, la situación de los museos etnológicos es muy débil (sin haber sido posible crear o consolidar hasta ahora museos etnológicos de carácter nacional catalán), mientras que por el contrario existe un buen número de pequeños museos etnológicos de carácter comarcal y local, muchos de los cuales tienen un gran interés. Resulta paradójico, por tanto, la inexistencia de museos nacionales etnológicos en contraposición al dinamismo de los museos locales (con iniciativas y ejemplos muy destacables), que desde los años ochenta han conocido una fuerte expansión y que han tenido un impacto importante en la renovación museológica. 
Es complejo determinar las causas que han llevado a esta situación. Como en todas partes, el desarrollo de los museos se puede explicar en función de las relaciones complejas entre el poder político, los especialistas y la comunidad que los sostiene (Pomian, 1990) y la evolución de los museos etnológicos catalanes no es ajeno a ello. Así, mientras que en el ámbito local, lo etnológico ha sido considerado con frecuencia como un elemento prioritario de la identidad local tanto por la propia comunidad como por los especialistas y en muchos casos por los mismos Ayuntamientos, en el ámbito catalán el patrimonio etnológico ha tenido siempre un papel secundario. Enfrente de la opción clara por los museos de arte o incluso de historia como elementos explicativos de la identidad, la historia reciente de los museos etnológicos catalanes puede escribirse como una sucesión fallida de intentos para crear un gran museo de carácter nacional. Ello puede resultar paradójico en una nacionalidad que se ha caracterizado desde muchos años atrás por una fuerte reivindicación de su identidad, pero parece que políticamente no se ha visto en los museos etnológicos una herramienta de afirmación de dicha identidad.

Pero estos factores no explican más que una parte de la realidad. En el ámbito local, el patrimonio etnológico comenzó teniendo en los años ochenta un fuerte carácter social para la reivindicación de las identidades locales (Alcalde y Rueda, 2012) y también ha sido visto y utilizado como un recurso para el desarrollo o el sostenimiento económico local (Prats, 2014:155). Ello ha permitido la activación de numerosas pequeñas iniciativas, en un contexto de afirmación de la localidad enfrente de la globalización, e incluso de afirmación de la ruralidad o del pasado industrial (Roigé y Frigolé, 2010). Por el contrario, a nivel más general y en el contexto de una gran ciudad como Barcelona, los museos etnológicos tienen un papel secundario por sus dificultades de competir con los grandes museos de arte -que entran dentro de una imagen moderna de aparador turístico- y por su dificultad de explicar la complejidad de las identidades en un contexto de unas identidades cambiantes, de multiculturalismo y de unas sociedades complejas y permeables.

Explicar estos cambios sociales debería ser una misión primordial de la museología etnológica, pero ello no se ha conseguido por las dificultades del relato de los museos de sociedad, de gestión política mucho más difícil que los aparentemente más neutros de arte (es por ello que algunos museos etnológicos se convierten, como veremos, en museos en los que los objetos se exponen por su valor estético). Por ello, con frecuencia los gobiernos no consideran prioritario la creación o inversión en estos museos porque sus contenidos o narrativas pueden resultar incómodos. Como señala Bergeron para el caso del Canadá (2014:136), las relaciones entre los discursos de los museos de sociedad y los gobiernos son con frecuencia turbulentas por la influencia de los museos sobre el público y por las dificultades de controlar sus discursos. Los gobiernos utilizan generalmente los museos para validar sus discursos y su posición ideológica, 
utilizándolos como empresas para difundir sus mensajes como sitios "fuera de toda sospecha" (Gob, 2007:331), presentándolos como sitios de autenticidad y de verdad, aunque ello comporta con frecuencia costes importantes por los debates que se generan. Y resulta paradójico que mientras que en el caso de los museos etnológicos y de sociedad estos debates acostumbran a ser intensos, en el caso de otros tipos de museos (como los de arte o de ciencia) los debates son menores, a pesar de que sus discursos ideológicos son también muy explícitos (Roigé, 2014). Resulta evidente, por tanto, que no ha existido un interés político ni social en la creación de grandes museos etnológicos en Cataluña ${ }^{1}$ por sus dificultades políticas y porque otros museos ya cumplen las funciones narrativas de la identidad nacional.

Añadamos dos razones más sobre las que volveremos más adelante. Primero, por el escaso interés de la Antropología como disciplina académica por la museología, con una visión distante, generalmente crítica. Y segundo, y más importante, el efecto de la crisis económica que se vive desde el 2007, que comporta una drástica reducción de los presupuestos públicos dedicados a los museos, y que está no sólo paralizando la creación de nuevos museos, sino afectando fuertemente a las actividades y a las posibilidades de supervivencia de muchos museos, en especial de los locales. Como instituciones culturales y científicas estrechamente relacionadas con lo político, los museos de etnología han vivido en las últimas décadas unas transformaciones sin precedentes (Mazé, Pulard y Ventura, 2013) que tienen que ver con la historia sociopolítica, el papel de las identidades nacionales y la identidad catalana y las circunstancias económicas en la que se han ido desarrollando.

En las páginas siguientes abordaremos algunas de estas cuestiones, analizando la situación y las polémicas recientes de los museos etnológicos en Cataluña. Trataremos de responder entre otras a las siguientes cuestiones: ¿Qué circunstancias políticas y socioeconómicas han condicionado su desarrollo? ¿Por qué se ha desarrollado una interesante museología local y por el contrario una muy escasa museología a nivel nacional catalán? ¿Qué ricamente ante las transformaciones de la sociedad sociedad es y a las posibilidades de supervivencia de muchos museos, en especinfluencias teóricas ha tenido la museología etnológica catalana? ¿Cómo representan y exponen la sociedad catalana y la sociedad local? ¿Cómo responden a los retos económicos que plantea la crisis económica? ¿Cuáles son los retos que se plantean conceptual y teóricamente ante las transformaciones de la sociedad, la globalización y las reivindicaciones políticas catalanas?

1. Las mismas consideraciones pueden hacerse respecto a otras autonomías en España, e incluso a nivel estatal. En España no existe ningún Museo Nacional de Etnología (Fernández de Paz, 2008), y el último proyecto previsto -que implicaba el traslado del museo a Teruel- quedó truncado con el cambio de gobierno. Una de las dificultades del proyecto consistía en qué debía explicarse sobre España. Algo similar ocurre en diversas autonomías, aunque sí existen iniciativas interesantes como el Museu Valencià d’Etnologia, el San Telmo Musea, Museu del Pueblu d’Asturies, Museo Etnográfico de Castilla y León, etc. 
El texto se divide en cuatro grandes apartados. Tras presentar una rápida evolución histórica de los museos etnológicos, para después abordar separadamente la situación y debates sobre tres grandes tipos de museos: los museos locales, los museos de otras culturas, y los proyectos fallidos de creación de un Museo Nacional de Etnología. Todo ello nos permitirá discutir, para concluir, los principales retos de estos museos y, en especial, cómo responden a la actual crisis financiera.

\section{LA EVOLUCIÓN DE LOS MUSEOS ETNOLÓGICOS}

Aunque nuestro propósito principal consiste en analizar la situación actual de los museos etnológicos, conocer algunos antecedentes nos permitirá comprender el panorama más reciente. Podemos señalar, a grandes rasgos, cuatro grandes períodos en la evolución de los museos. Primero, antes de 1975, con un débil desarrollo de la museología etnológica, limitada a algunos casos. En segundo lugar, después de 1975, que comportó en los ochenta la creación de un gran número de museos etnológicos -sobre todo localescomo consecuencia del fortalecimiento de las identidades tras la instauración del sistema democrático en 1977. La nueva museología inspiró todos estos museos de fuerte base social, en el marco de unas sociedades que durante aquellos años se encontraban en un fuerte proceso de transformación y de redefinición (Roigé, Arrieta y Abella, 2012). Posteriormente, entre los años 1990 y 2007, los discursos de identidad continuaron siendo importantes, pero el número de los museos creció considerablemente como consecuencia de la evolución económica. Finalmente, el impacto de la crisis económica ha comportado una drástica reducción de los presupuestos dedicados a los museos en general y la necesidad de un replanteamiento de la museología etnológica.

\subsection{Antecedentes}

Antes de 1975, el desarrollo de los museos etnológicos fue muy limitado. Las razones son diversas, pero creemos que debemos señalar sobre todo cinco factores explicativos: el papel poco relevante que tuvo el folklore desde una perspectiva académica, el tardío desarrollo de la antropología académica, el escaso papel del colonialismo español en el momento en que se construyeron las grandes colecciones etnográficas sobre otras culturas (finales del XIX/principios del XX), las prohibiciones por parte del Estado español de toda representación de la identidad catalana (sobre todo durante las dictaduras de Primo de Rivera y Franco), y el papel poco relevante que jugó la museología en los movimientos nacionalistas y regionalistas catalanes, al contrario del papel desarrollado por ejemplo en los países nórdicos, donde los museos y el folklore jugaron un papel esencial en sus reivindicaciones nacionales.

Así y todo, sí hubieron diversas iniciativas. Los primeros proyectos de museos específicamente etnográficos se iniciaron a principios del siglo $\mathrm{XX}$, a raíz de la iniciativa 
de un grupo de folkloristas que sintieron y expusieron la necesidad de crear centros de explicación e interpretación de la realidad cultural, social y económica de las sociedades tradicionales. Así, en 1916-1918, el Arxiu d'Etnografia i Folklore de Catalunya [Archivo de Etnografía y Folklore] y el Centre Excursionista de Catalunya propusieron la creación de un museo etnográfico catalán, propuesta recogida por el gobierno regional de la Mancomunitat de Catalunya, que llegó a aprobar la creación de dicho museo. La Dictadura de Primo de Rivera frenó estos proyectos, al considerarlos relacionados con la identidad catalana, por lo que la creación efectiva de un museo etnográfico tuvo que esperar hasta 1929 con la inauguración del Museu Etnogràfic i Folklòric de Ripoll, un proyecto en consonancia con las tendencias europeas de la época, y que con el tiempo se ha convertido en un museo de referencia. Poco después, ya coincidiendo en plena II República, se proyectó la creación de un Museu Folklòric de Catalunya (1934), y casi al mismo tiempo se creó la Sección de Etnología del Museu Arqueologic.

Todos estos museos no se desarrollaron plenamente hasta después de la Guerra Civil: el de Ripoll no se abrió al público hasta 1942, mientras que el de Artes y Tradiciones Populares de Barcelona también en 1942, y el Museo Etnológico de Barcelona en 1949. En pleno franquismo, la creación de estos museos resulta paradójica, pero el folklore no fue visto como una amenaza a la uniformidad de España por su discurso generalmente conservador y una visión de la sociedad uniforme y predominantemente rural (Ortíz, 1997). La erudición folklórica, como sostiene Geniola (2014) fue consentida por el régimen como una exaltación folklórico-espiritual y erudito-elitista de dimensiones superpuestas y escalonadas, fue en cierta manera un "nacionalismo regionalizado". Así y todo, el folklore y el derecho foral jugarían un papel ambivalente, puesto que a pesar de que eran tolerados por el régimen jugaron un papel significativo en el mantenimiento de un sentimiento regionalista en Cataluña (Geniola, 2014).

Fue el etnógrafo Ramon Violant quien proyectó el Museo de Artes y Tradiciones Populares, que tuvo su sede incial en el recinto del Pueblo Español (una recreación de arquitectura popular a inspiración de Skansen, construida para la Exposición Universal de 1929). Para ello, se realizaron diversas campañas de adquisición de objetos materiales de cultura popular de diversas regiones catalanas. El museo se inauguró en 1942 (Serra, 2010:38), siendo su obra más emblemática la creación de la denominada Casa Pallaresa, reproducción de una casa pirenaica.

Aunque todo ello ocurría en pleno franquismo, el museo contenía ya algunas de las características de los museos etnológicos posteriores, representado sobre todo una sociedad tradicional rural como equivalente a la sociedad "tradicional" catalana: "en el sentido patriótico debemos decir que un país se honora a sí mismo, como dice Aranzadi, 
enseñando sus raíces identitarias propias" (Violant, 1946, citado en Rueda, 2007:128). La visión de Violant entroncaba con las tendencias museológicas de la época, influenciada sin duda por el ATP de París, creado en 1937 (Juan, 1998), con una museología moderna que pretendía mostrar la vida cotidiana y los distintos elementos de la sociedad de forma pedagógica y evolutiva ${ }^{2}$. Violant entendía que los objetos no debían ser expuestos por su belleza, sino de manera "que dijesen algo al público, de manera que al contemplarlos aprendiesen algo" (citado en Rueda, 2007:128). Como dice Rueda (2007:129), "podríamos decir que hasta después de la democracia, los museos actuales no han conseguido un discurso tan integrado y completo".

Mientras que Violant conducía la propuesta etnográfica sobre la sociedad catalana, otro etnólogo, August Panyella, encabezaba la realización de un museo dedicado a las entonces denominadas sociedades "exóticas", en el contexto de la etapa final del colonialismo español. En 1949 se creaba el Museo Etnológico y Colonial de Barcelona, también bajo el impulso del Ayuntamiento. Entre los años 1950 y 1980 se llevaron a cabo varias series de campañas etnográficas ${ }^{3}$, en Marruecos, Guinea Ecuatorial, Nepal, India, Afganistán, Turquía, Perú, Bolivia, Etiopía y Senegal con la ayuda de otros colaboradores, como Eudald Serra y Albert Folch (Ortiz, 1995). La historia de ambos museos -que resumen dos tradiciones de museos etnológicos, uno dedicado a las propias culturas y otro a las sociedades "exóticas"- fue cruzándose a lo largo de la historia. En 1962, ambos museos fueron unificados, mientras que en 1982 volvieron a dividirse, para reunificarse de nuevo en 1999. Como puede verse, a lo largo de todos esos años fue el Ayuntamiento de Barcelona quien impulsó la creación de todos estos proyectos. Este papel de la municipalidad no sólo se ha dado en los museos etnológicos, sino en buen número de museos. Durante el franquismo, el Ayuntamiento barcelonés fue la principal entidad impulsora de museos en Cataluña: a falta de proyectos del Estado - poco interesado en museos, y en todo caso sólo en museos en Madrid- fueron el municipio y la Diputación Provincial quienes mantuvieron e impulsaron los museos más destacados en Cataluña.

Mientras tanto, a partir de la segunda mitad de los años cincuenta y sobre todo desde los

2. Para conseguir sus objetivos dividía el museo en dos secciones: cultura material y espiritual (lo que hoy llamaríamos inmaterial). En la primera expondría aspectos como la vivienda humana, el mobiliario doméstico, las primeras industrias (caza, pesca, ganadería, agricultura), para terminar con las industrias populares o artesanas. En la parte espiritual mostraba la vida de los individuos desde el nacimiento a la tumba, pasando por el matrimonio y la vida familiar, así como los rituales, la música, la danza, el teatro, las supersticiones, la medicina y la religiosidad.

3. Al principio, el Museo acogió varias colecciones reunidas por prohombres de Cataluña durante la segunda mitad del siglo XIX en Filipinas, la Guinea Española, Ecuador y Perú, incluyendo los objetos procedentes del Pabellón Misional de la Exposición de 1929 (Serra, 2010:43) 
sesenta se crearon toda una serie de museos territoriales de base etnográfica ${ }^{4}$, muchos con aspiración comarcal y de carácter general. Estos museos representaron el inicio de la recuperación a nivel local por los elementos territoriales y el patrimonio etnológico, y tuvieron un papel muy destacado frente al uniformismo, hasta el punto que pueden considerarse como focos de resistencia identitaria y de activismo cultural. Ya en los finales del franquismo, en los setenta, se fueron sentando las bases de una museología local que acabaría desarrollándose ya en la Transición. Con todo, como señala Rueda (2007:131), estos museos tenían como defecto sus débiles presentaciones museográficas, la falta de estudios documentales y la desconexión con la antropología académica (prácticamente inexistente), algo que ha tenido consecuencias nefastas en la museología del país.

\subsection{5-1990}

Tras la muerte de Franco en 1975, la transición a la democracia fue un momento trascendental en la configuración y renovación de los museos. Los cambios democráticos provocaron una importante euforia cultural y un gran interés por el patrimonio, tanto a nivel nacional catalán como a nivel local, lo que comportó la creación de un gran número de museos locales y comarcales que hacían referencia a la tradición y la identidad local. La proliferación de estos museos, la mayoría de los cuales surgieron a partir de iniciativas sociales y gran dosis de voluntarismo, fue sin duda la característica más significativa de la museología durante aquellos años (Iniesta, 1994). Dos hechos estrechamente relacionados contribuyeron decisivamente a esta proliferación de museos locales: la reinstauración de la Generalitat y la implantación de los nuevos ayuntamientos democráticos. La reivindicación de la identidad catalana y local comportó la creación de un gran número de museos locales, como una forma relativamente rápida de actuar en el territorio frente a los rápidos cambios que estaban experimentado las sociedades rurales.

La proliferación de museos se tradujo en la creación de la Xarxa de Museus Locals $i$ Comarcals [Red de Museos Locales y Comarcales] a partir de 1983. Según Rueda (2007:132-133) durante este período se crearon nueve museos territoriales nuevos y se reformaron trece. La Red llegó a contar con veinte museos territoriales, la mayoría de ellos de carácter etnológico.

4. Museu de la Pell i Comarcal de l'Anoia (1954), Museu de la Marina de Vilassar (1955), Museu del Montsià (1956), Museu Comarcal de la Concal de Barberà (1958), Museu de Calella (1961), Moseu Molí Paperer de Capellades (1961), Museu Comarcal de l'Urgell (1962), Museu Comarcal de Berga (1962), Museu de la Noguera (1968), Museu del Suro de Palafrugell (1972), Museu dera Val d'Aran (1973), etc. Muchos de estos museos fueron renovados con el advenimiento de la democracia. 


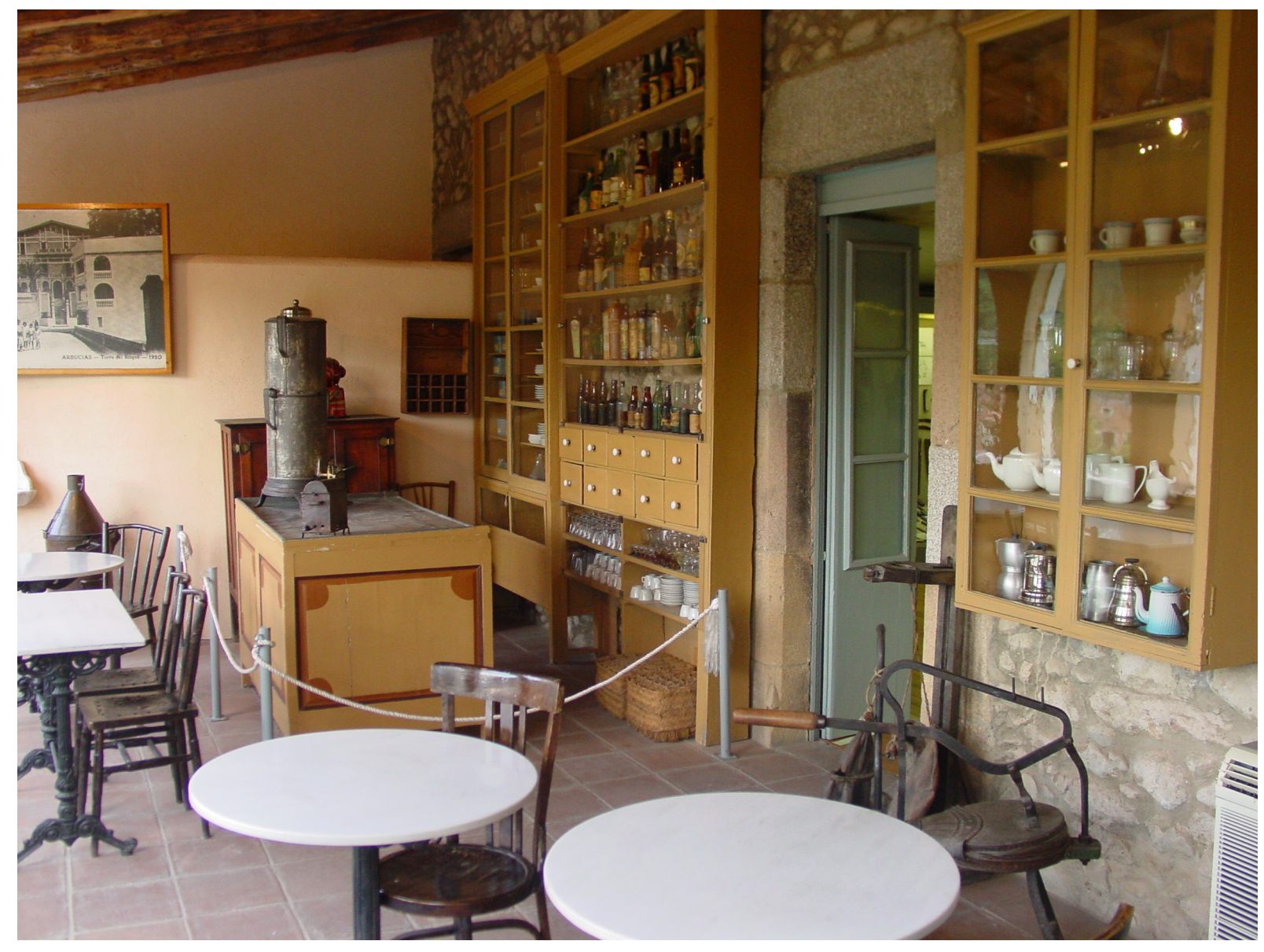

Foto 1: Uno de los bares de la vida local, ahora en el Museu Etnològic del Montseny, Arbúcies. El museo es un claro exponente de los museos creados en los años ochenta, con una clara proyección social a iniciativa de una asociación local.

Aunque la mayoría de estas instituciones contaban con recursos muy limitados, muchas de las iniciativas fueron un elemento importante de sensibilización y de renovación museológica, en línea con las bases teóricas de la "nueva museología". Como se conoce, el movimiento de la nueva museología constituyó un revulsivo importante en la historia de los museos, al señalar la necesidad de unos museos basados en el territorio, con la participación de la comunidad local y la creación de nuevos tipos de museos, como los ecomuseos (Rivière, 1989; Moutinho, 1986). En este sentido, la ecomuseología -que combina el patrimonio natural con el etnológico y cultural en edificios in situ y le da un valor muy destacado a la participación de la comunidad local (Desavellées y Mairesse, 2002)- tuvo una destacada influencia, sobre todo en Cataluña, donde se crearon no sólo ecomuseos como el Ecomuseu de les Valls d'Àneu (proyectado a fines de los 80, abierto en 1994), sino también un gran número de museos locales basados en los principios de la "nueva museología", como el Musèu dera Val d’Àran (en los Pirineos, un valle de lengua occitana con una fuerte identidad, reformado en1984), el Museu del Montsià (en el Delta del Ebro, reformado en 1983), o el Museu Etnològic del Montseny (en un parque natural 
declarado Reserva de la Biosfera, 1984), entre otros muchos (Alcalde y Rueda, 2012:1-8; Andreu, 2007; Rueda, 1992).

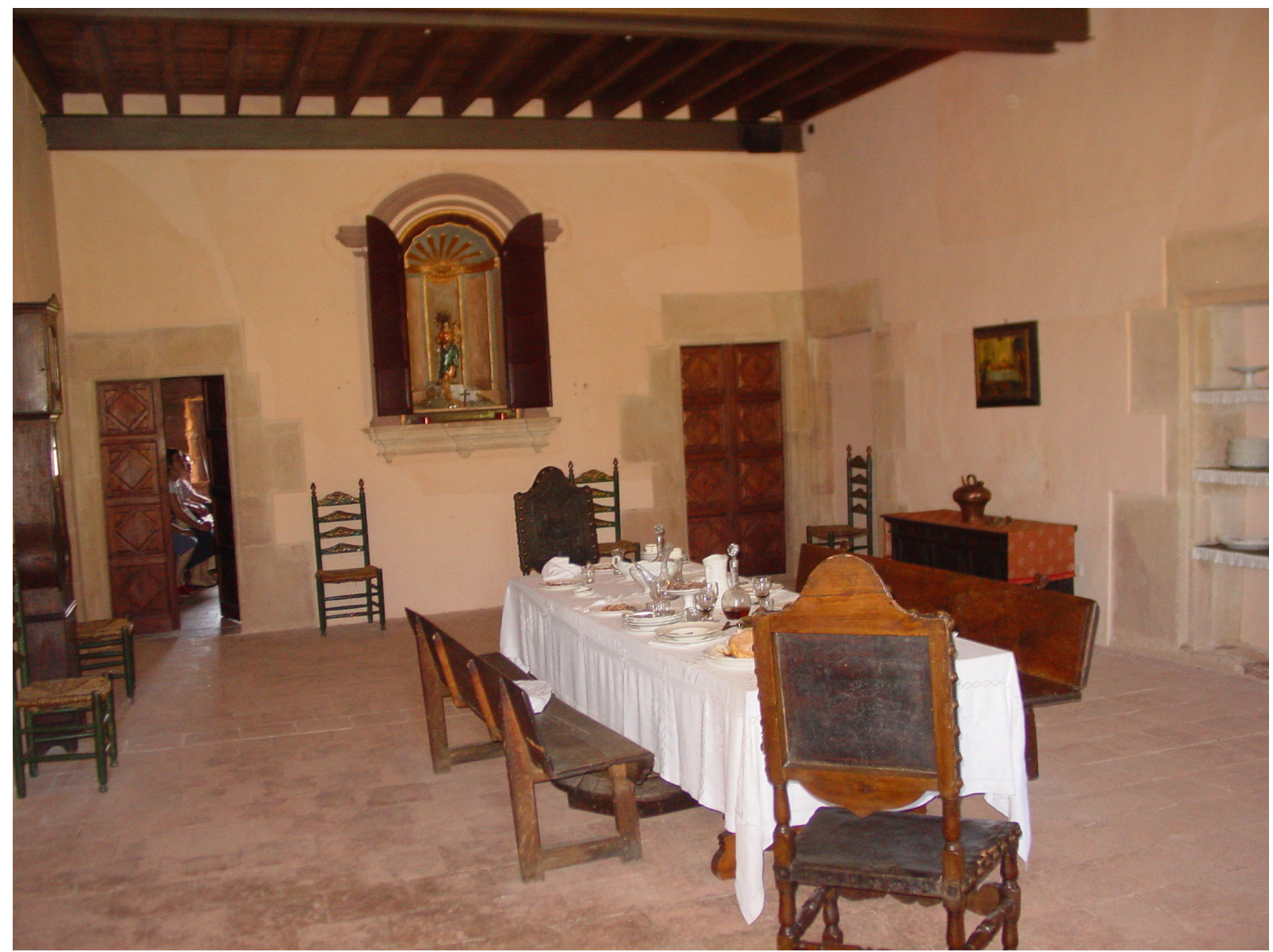

Foto 2: Mas L'Agustí, El Montseny. Masía musealizada como explicación de la vida rural "tradicional". Museo creado por la Diputació de Barcelona, dentro del Parc Natural del Montseny. (Foto: Xavier Roigé)

\section{3. $1990-2007$}

A partir de los noventa, se produjeron cambios muy significativos en la política de museos en Cataluña (Prats, 1995). Si en el período anterior la apuesta más importante del gobierno catalán fueron los museos locales, a partir de los años noventa comienza el proceso de consolidación de la autonomía y el proyecto de creación de unos museos de carácter nacional. Se preveía la creación de un Museo Nacional de Etnología que, como veremos, nunca ha llegado a realizarse. La promulgación de la Ley de museos aplicó un nuevo modelo de planificación museística, basado en redes temáticas que tenían sus cabeceras en los museos nacionales, lo que comportó una cierta decadencia temporal del modelo territorial (Rueda, 2007:133), al destinarse la mayor parte de los recursos a los grandes museos nacionales, en especial el de Arte y el de Ciencia y Técnica. Al mismo tiempo, el proyecto de creación de Barcelona como destino cultural implicaba la creación de nuevos equipamientos culturales, privilegiándose los museos destinados al turismo. 
Con todo, el crecimiento del número de museos locales continuó siendo considerable gracias a la iniciativa municipal, en gran parte bajo la idea de creación de elementos de desarrollo local. La creación de nuevos museos o la reforma de antiguos museos fue aún más intensa durante los primeros años del siglo XXI. Entre el 2000 y el 2007 se produjo una auténtica inflación patrimonial, con proyectos que buscaban una mayor originalidad y modernidad. Esta inflación patrimonial no sólo ha creado, en cierta manera, una auténtica "burbuja museística", sino que ha cambiado absolutamente el panorama museístico, pasando de una museología de fuerte inspiración social a una museología de raíz económica, planteada sobre todo al servicio del turismo.

Además, las características de los museos han ido cambiando. Si en las décadas anteriores los museos fueron el resultado de iniciativas sociales, ahora los museos locales han sido generalmente el resultado de proyectos de instituciones públicas con el objetivo de desarrollar el turismo o de contribuir al desarrollo social. Muchas pequeñas localidades crearon infraestructuras museísticas, especialmente centros de interpretación, en muchos casos sin una adecuada planificación ni cálculo de las posibilidades de mantenimiento, de supervivencia y de captación de públicos. A nivel local, fueron los museos dedicados al patrimonio etnológico (especialmente al rural), los museos de patrimonio industrial y los de memoria histórica.

La tendencia de esos años no solo incidió en el crecimiento del número de museos. Durante esos años se produjo una marcada tendencia a la externalización de servicios, creándose un gran número de empresas museísticas dedicadas a la realización de proyectos, exposiciones, o servicios didácticos. Esta externalización implicó que un gran número de museos fuesen creados bajo la óptica de la lógica empresarial, más que bajo la lógica local o comunitaria. Resulta sintomático, por ejemplo, que gran parte de esas infraestructuras se denominasen "centros de interpretación" y que por el contrario el número de ecomuseos creados fuese muy bajo. Eran las propias empresas quienes diseñaban los productos, las escenografías e incluso los temas. Como resultado, en el panorama local contamos con un gran número de "museos de diseño", pero menos imbricados en la dinámica local. Fueron productos diseñados para ser vistos, dirigidos sobre todo a un público turístico. La lógica económica parecía triunfar sobre la lógica comunitaria, y las pequeñas comunidades locales confiaron en la expansión de un turismo rural que debía consumir productos patrimoniales.

Incluso después de iniciarse la crisis, el número de museos fue incrementándose. La mayoría son proyectos que estaban iniciados y que, pese a la coyuntura adversa, han podido ser finalizados. Ya en plena crisis, entre el 2008 y el 2012 se han creado hasta 40 nuevos museos en Cataluña, de los cuales la mitad son centros de interpretación museográficos, mientras que más de 30 centros han reformado, renovado o ampliado las salas de exposición (Montañés, 2012). Esta fiebre de museos, ¿fue excesiva? ¿Es 
demasiado el número de museos? ¿Hasta qué punto la sociedad catalana necesita tantos museos?

\subsection{Museos ante la crisis (desde el 2008)}

Con la aparición de la crisis económica el panorama ha cambiado radicalmente. Desde 2008, los museos han visto cómo la inversión, los presupuestos y los gastos ordinarios de mantenimiento son cada vez más bajos. Un gran número de museos han disminuido sus actividades, sus exposiciones e incluso sus horarios de apertura, al tiempo que se han destruido puestos de trabajo.

Resulta interesante constatar que los museos en mayores condiciones para sobrevivir son los grandes museos que viven del turismo y los pequeños museos, con pocas estructuras pero con fuerte base comunitaria, y entre ellos se encuentran los ecomuseos y los museos etnológicos creados con una base comunitaria más sólida, mientras que aquellos que fueron creados con un menor apoyo social se encuentran en peor condiciones. Como dice Bergeron (2009), los museos con fuerte base social tienen mejores condiciones para sobrevivir y adaptarse a unas condiciones económicas adversas.

Las condiciones, con todo, son muy duras para muchos museos locales, que deben hacer frente a una fuerte disminución de subvenciones públicas mediante reducciones de personal, trabajo a tiempo parcial y, sobre todo, disminuyendo sus actividades más costosas (exposiciones temporales, publicaciones, investigación, etc.). No tenemos datos específicos de cuánto ha supuesto la disminución específica de los presupuestos de los museos etnológicos, pero si nos fijamos en los datos globales de la financiación pública de museos, en sólo tres años, entre el 2010 y el 2013 el presupuesto de los fondos públicos ha descendido un $29,3 \%$. Por otra parte, otro dato significativo es que los museos catalanes están financiados mayoritariamente por los Ayuntamientos (en un 59,9\%) y en menor medida por la Generalitat $(28,9 \%)$ y por las Diputaciones $(11,2 \%)$. En el mismo período, la financiación que más ha decrecido en términos porcentuales ha sido la del gobierno autónomo (-31,2\%), y algo menos la de los Ayuntamientos $(-28,7 \%)$ y la de las Diputaciones (-27,5\%). Estas cifras indican, por una parte, que el recorte de los presupuestos es muy elevado, incidiendo sobre todo en las actividades cotidianas, y por otra parte que el esfuerzo de financiación de los museos catalanes recae sobre todo en los Ayuntamientos, casi en un $60 \%{ }^{5}$. La magnitud de la disminución es, no obstante, mayor en el caso de los museos etnológicos locales. Además de los presupuestos provenientes de Cultura destinados a museos, éstos han perdido otras partidas provenientes de patrimonio etnológico, de investigación, de desarrollo rural, etc. En algunos casos, algunos museos

5. Datos de elaboración propia, a partir de IDESCAT: Anuari estadístic de Catalunya: Despesa pública en cultura. Per administracions i àmbits d’actuació. http://www.idescat.cat/pub/?id=aec\&n=795. [Consulta:31-8-2015]. En concreto, en el 2010 la Generalitat destinaba a museos 47.844,22 millones de euros, las Diputaciones 17.551,5, y los Ayuntamientos 95.503,81, con un total de 160.899,53. Las cifras para el 2013 eran respectivamente de $32.914,8,12.723,8$ y 68.103,6, con un total de $113.742,2$ millones. 
etnológicos locales han perdido el $50 \%$ de sus ayudas, debiendo añadirse las pérdidas de entradas por la disminución del público también por efecto de la crisis.

Por otra parte, la crisis cuestiona también los contenidos y los propios objetivos de los museos etnológicos, que deben realizar un difícil equilibrio entre sus objetivos sociales, los intereses del público, la financiación pública y la necesidad de conseguir nuevos recursos. De ello trataremos más específicamente al final de este artículo.

\section{LOS MUSEOS ETNOLÓGICOS LOCALES}

\subsection{Las características de los museos etnológicos locales}

Desde los años 1990, y en el momento actual, son diversos los retos de los museos locales. Por una parte, está la necesidad -acrecentada con la crisis económica- de contribuir a la generación de recursos y a la transformación del patrimonio, incluso en algo rentable. Todos estos museos están sometidos a tensiones diversas como son el equilibrio entre el servicio a la comunidad local y su uso turístico, la construcción de la identidad local en base a las formas del pasado y unas comunidades actuales muy distintas, la tensión entre lo local y lo global, y la ilusión de su personal por el proyecto local enfrentado a una frecuente falta de medios (Rasse, 2000).

De las 548 instituciones reconocidos como Museos o Colecciones ${ }^{6}$ en Cataluña (112 museos y 436 colecciones) el 37\% tiene parte de sus colecciones como etnológica (49 museos y 159 colecciones). Aunque son el tipo de museos mayoritario, son al mismo tiempo el tipo de museos que recibe un menor número de visitantes: 1.487 como promedio (con una media de 13.216 visitantes anuales en cuanto a los museos, enfrente de la media general de 92.514; y de 1.244 en cuanto a las colecciones, enfrente de una media de 25.762 visitantes) ${ }^{7}$.

Los más visitados son el Museu del Joguet (Museo del Juguete, en Figueres, con 51.065), el Museu de la Pesca de Palamós (36.796), el Museu del Suro (Museo del Corcho de Palafrugell, 28.501), y el Museu Molí Paperer (Museo Molino del Papel, Capellades, $27.975)^{8}$. Otros más específicamente etnológicos locales tienen alrededor de los 10.000 vi

6. La legislación catalana en museos distingue entre dos categorías de equipamientos museológicos: los "Museos" y las "Colecciones". Incluimos los datos de ambas categorías agrupados.

7. Fuente: elaboración propia a partir de Departament de Cultura: Estadística de museus. http:// cultura.gencat.cat/ca/departament/estructura_i_adreces/organismes/dgpc/temes/museus/servei_de_ museus_i_proteccio_de_bens_mobles/estadistiques_de_museus_70_pdf/[Consulta: 31-8-2015]

8. No se han incluido los datos de los museos marítimos, como los de Barcelona (298.525), que a pesar de aparecer clasificados como museos etnológicos tienen una dimensión distinta. Tampoco hemos incluido en la lista los museos de patrimonio industrial porque no aparecen como etnológicos, a pesar de que entendemos que deberían considerarse como tales. Citemos, por ejemplo, el Museu de les Mines de Cercs, con 36.741 visitantes. 
puesto que no siempre -ni antes de la crisis- estos museos consiguen la atracción de público ni los objetivos de desarrollo económico que se propusieron (Prats, 2014:159).

Uno de los principales problemas de los museos etnológicos locales es su aislamiento y su dimensión. En el 2008 se creó la Xarxa de Museus d'Etnologia de Catalunya [Red de Museos de Etnología], constituida por el Museu de la Mediterrània, el Museu de la Pesca de Palamòs, el Ecomuseu de les Valls d’Àneu, el Museu de la Vida Rural, el Museu Comarcal de la Conca de Barberà, el Museu de la Vida Rural, el Museu de les Terres de l'Ebre, el Musèu dera Val d'Aran, el Museu Etnogràfic de Ripoll, el Museu Etnològic de Barcelona, el Museu Etnològic del Montseny-La Gabella y el Vinseum-Museu de les Cultures del Vi. Se trata de distintos museos ubicados en pequeñas y medianas poblaciones catalanas y que han conseguido a lo largo de su trayectoria una excelente proyección pública y un trabajo importante con la comunidad. Se trata de los museos etnológicos más bien situados a nivel de museografía, de proyección pública y de investigación. El trabajo en red pretende poner energías en común a nivel expositivo, de conservación y de investigación. El trabajo en red es, sin duda, una de las mejores alternativas para la continuidad de estos museos.

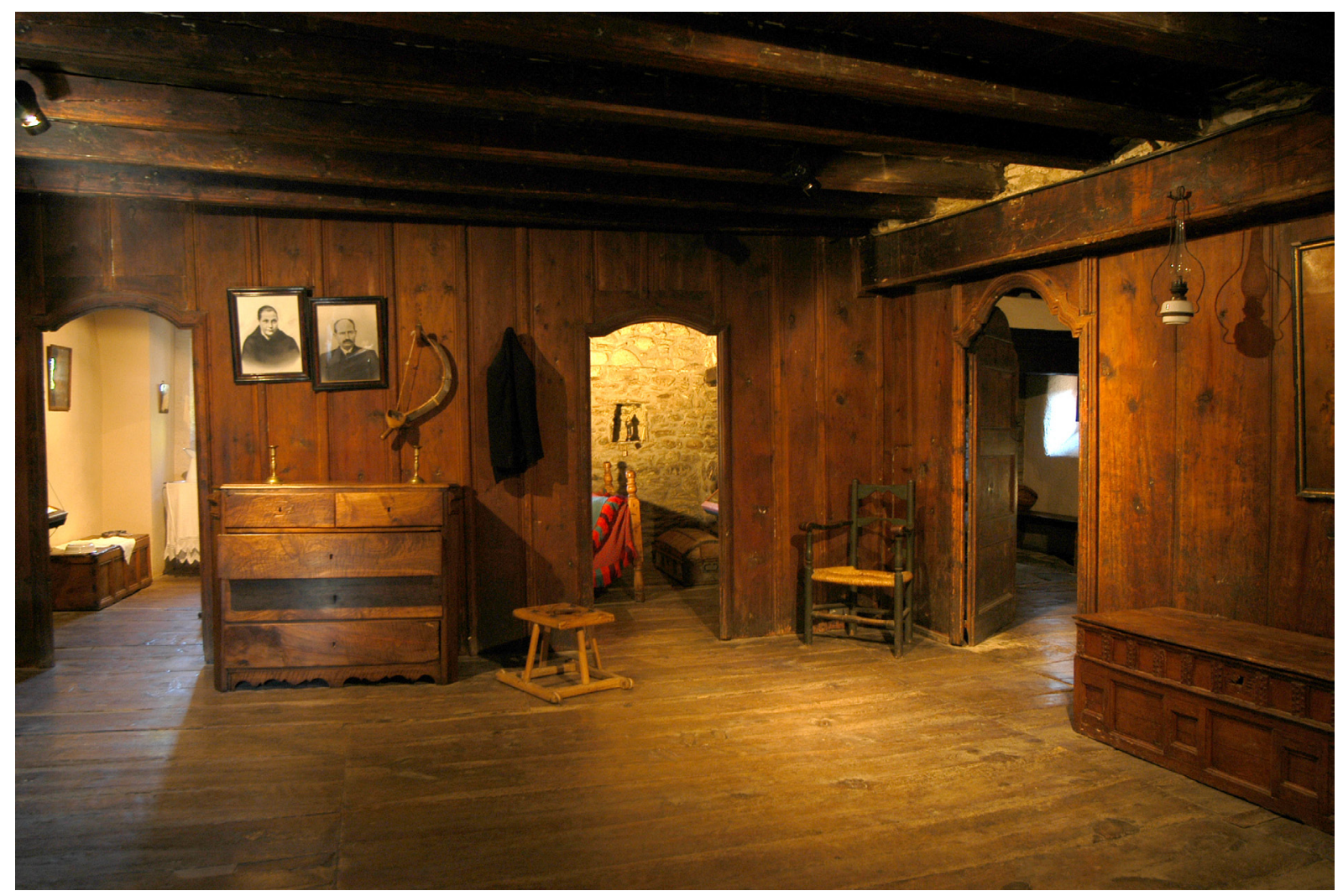

Foto 3: Casa Gassia. Centro principal del Ecomuseu de les Valls d’Àneu, Esterri d’Àneu. Uno de los museos de Red de Museos de Etnología y un claro referendete de la influencia de la ecomuseología. (Foto: Ecomuseu de les Valls). 


\section{2. ¿Qué imágenes nos dan sobre la sociedad local?}

¿Pero qué imagen ofrecen los museos etnológicos locales de la sociedad catalana? La mayoría nos presentan una visión centrada en lo que se denomina la "cultura popular", con espacios dedicados a las actividades agrícolas, con muestras de utensilios, reproducciones de mobiliarios y de espacios de casas de distinto tipo, talleres artesanos, colecciones de trajes y otros elementos del folklore. Planteados muchas veces como una mirada nostálgica al pasado rural, el interés en la creación de estos museos constituyen una respuesta al proceso de globalización y al temor de la pérdida de los elementos de la cultura rural.

Los viejos museos de objetos rurales han envejecido no sólo formalmente, sino sobre todo en sus contenidos: las sociedades "tradicionales" e idílicas quedan ya muy lejos de los públicos actuales, incluso de los propios campesinos. La modificación de la mirada "tradicional" hacia lo rural no es simple, porque esta mirada es el resultado de una empresa política, económica, simbólica e ideológica. La patrimonialización de la sociedad rural se ha convertido en un nuevo instrumento de desarrollo local, pero al mismo tiempo en un nuevo creador de discursos sobre lo rural (Roigé y Frigolé, 2010). Y los museos, consciente o inconscientemente, están contribuyendo con frecuencia a la patrimonialización creciente de la sociedad rural, proporcionando una legitimidad a estos procesos.

Aunque muchos museos rurales siguen presentando una sociedad congelada e idealizada (Roigé y Arrieta, 2014), otros intentan hablar también del presente. La necesidad de cambio y de actualización de sus contenidos les lleva a explorar discursos sobre las transformaciones de la sociedad rural, sobre los procesos agrícolas de hoy y sobre los retos de la agricultura. Los museos comienzan a hablar de los retos económicos de la agricultura, de los cultivos ecológicos, de los sistemas productivos, de la globalización de la agricultura, o del uso de los transgénicos. Un cambio de planteamiento que tiene que ver también con los discursos científicos contemporáneos sobre la ruralidad y con los diversos modelos explicativos de su evolución (Jean, 1997). Así, el Museu de la Vida Rural (Museo de la Vida Rural, en L'Espluga de Francolí, Cataluña), renovado en el 2010 con el anexo de nuevas salas dedicadas a la transformación del campo en la era industrial, en las que se explica la evolución de las técnicas de producción agrícolas y también reflexionando sobre la vida rural de hoy. A partir de narraciones en primera persona, los testimonios nos hablan de aspectos tan diversos como el aprovechamiento de los residuos, los problemas de los transgénicos y la protección de semillas, la agroecología, del comercio de proximidad, del slow food o de las energías renovables. La visita termina con un enorme calidoscopio visual en el que se explican algunos de los retos ecológicos de la agricultura para contribuir -como se dice en la exposición- "a una reflexión sobre lo que hemos hecho y debemos realizar si no queremos agotar los recursos del planeta" ${ }^{9}$.

9. Web del Museu de la Vida Rural: http://www.museuvidarural.com/cainicio [Consulta:31-8-2015]. 


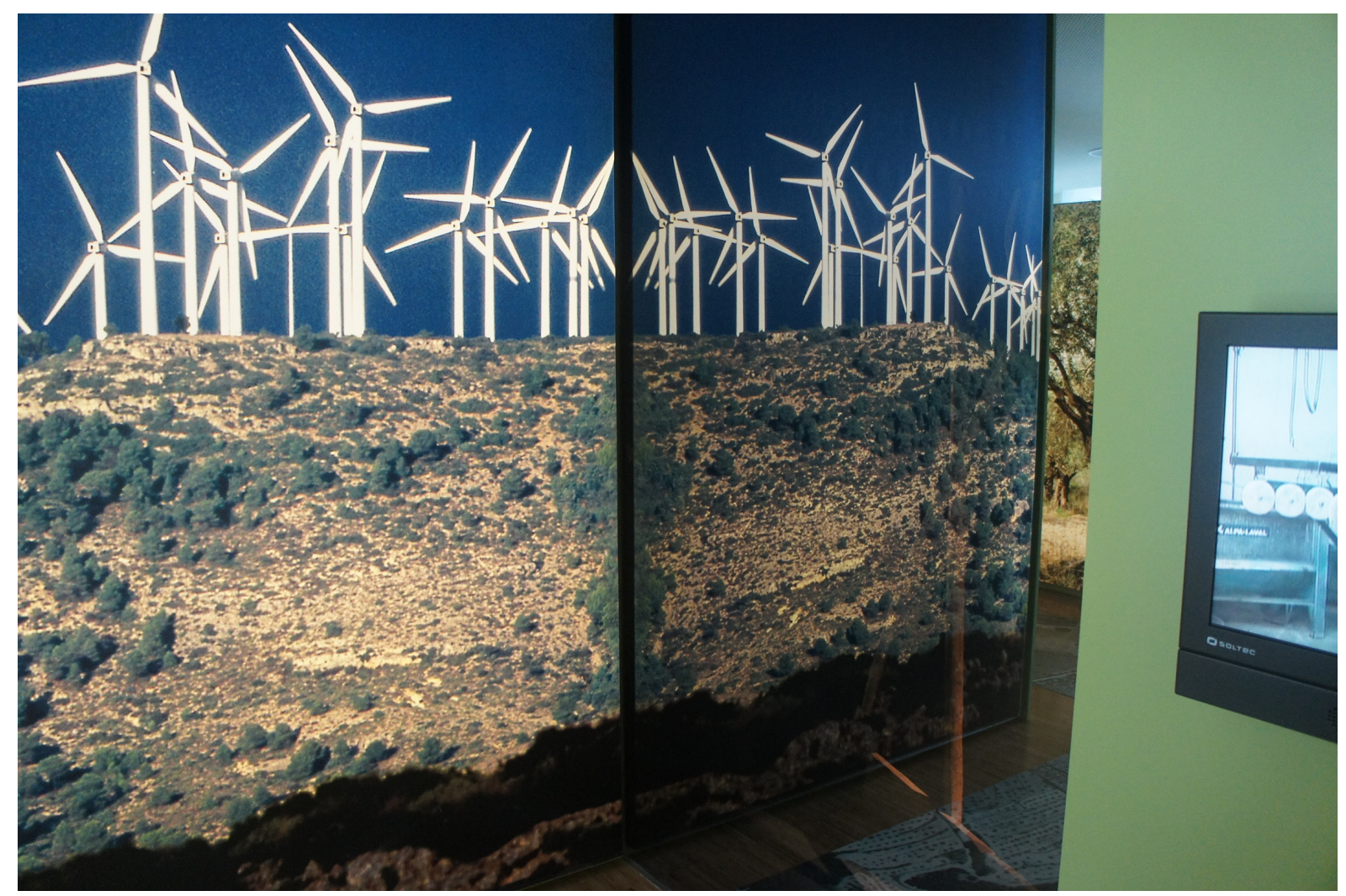

Foto 4: Museu de la Vida Rural, L’Espluga de Francolí. Presentación sobre la sociedad rural actual y los nuevos retos de la agricultura. (Foto: Xavier Roigé)

En una línea similar el museo Vinseum, en Vilafranca del Penedès, nos habla de las condiciones de producción del vino en la actualidad, y el Museu de la Pesca de Palamós se preocupa también de mostrar -además de los sistemas tradicionales de pesca- las condiciones actuales de la producción pesquera. Es cierto que una gran parte de los museos ofrecen una imagen congelada y arcaica de estas sociedades, pero muchos museos han intentando con mayor o menor éxito fórmulas para hablar del presente y modernizar sus discursos. Los museos etnológicos han avanzado mucho en sus discursos y nuevas generaciones de museólogos formados como tales en la universidad van dejando su huella en esta lenta transformación. Sin duda no todos los museos están en condiciones de abordar estos retos: las dificultades conceptuales, discursivas y museográficas son muchas, incluso las propias preferencias de unos públicos que contemplan los museos como instituciones del pasado y no del presente.

Además de los museos de temática rural, desde los ochenta se ha producido un creciente interés por el patrimonio industrial. Este tipo de patrimonio, no siempre considerado como patrimonio etnológico, se ha desarrollado rápidamente por el hecho de que con la transformación industrial se han quedado obsoletos un gran número de industrias, talleres o incluso industrias artesanas que configuraban la identidad económica de una 
zona, lo que no sólo ha dejado a muchas zonas con dificultades económicas (que los museos industriales han intentado paliar buscando nuevos recursos), sino también con problemas de identidad que estos museos han contribuido a fijar. Este tipo de patrimonio, además, resulta generalmente muy atractivo, y además es mucho más próximo para su comprensión por las clases obreras o medias. Desde la perspectiva del patrimonio etnológico, el problema de estos museos es que la etnología no ha sabido o no ha podido contemplarlos como museos propios. Un ejemplo claro es, en Catalunya, el Museu de la Ciència i la Tècnica (Museo de la Ciencia y la Técnica) que engloba una red de veinticinco pequeños museos que en muchos casos podrían estar incluidos en una red de museos etnológicos.

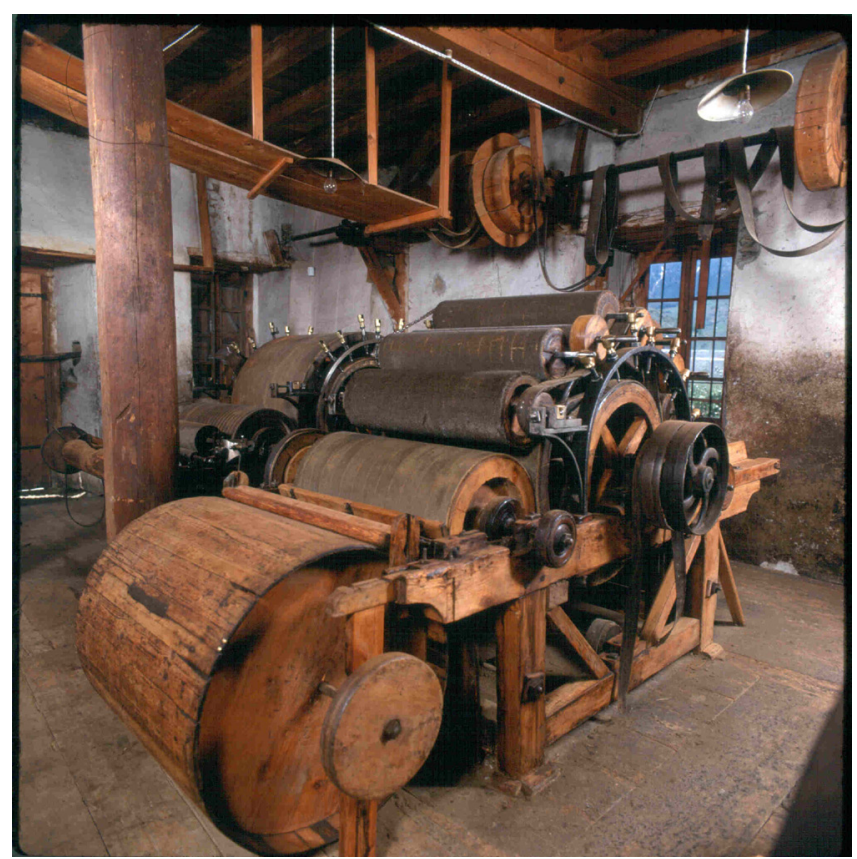

Foto 5: Fabrica dera Lana. Musèu dera Val d'Aran, Vielha. Un ejemplo de la proliferación del patrimonio industrial. (Foto: Xavier Roigé)

\section{LOS DEBATES SOBRE LA CREACIÓN DE UN MUSEO NACIONAL DE ET- NOLOGÍA}

Mientras que la museología etnológica local, a pesar de sus limitaciones, tiene una cierta presencia, resulta paradójico el escaso desarrollo de los museos etnológicos de carácter nacional catalán. En diversas autonomías se han creado museos con el objetivo de presentar los elementos de la identidad nacional o regional, pero en Cataluña no se ha desarrollado hasta el presente.

Todas las iniciativas planteadas, además, han sido fuertemente debatidas. En 1993 se realizó una primera tentativa, mediante un Seminario al que asistieren agentes diversos 
del entorno de la Etnología (universidad, museos, centros de investigación, entidades, personas significadas, políticos, expertos y profesionales, entre ellos diversas personas antropólogas), para concretar la misión, objetivos, modelo conceptual y política de exposiciones del proyectado museo (Ventosa, 1994). Más que el propio debate, el proyecto tuvo una notoria repercusión en la prensa, donde se criticó su contenido identitario. Tal vez por ello, el proyecto quedó aparcado y la Generalitat prefirió la construcción en un tiempo récord de un Museu d'Història de Catalunya, creado en 1996, y que representaba la misma identidad con una polémica seguramente menor.

La propuesta del museo etnológico no volvió a formularse hasta muchos años después, hasta finales del año 2007, con la aprobación de un Plan de Museos con dos propuestas importantes para el gran trayecto de la museología etnológica catalana: la creación de la Red de Museos de Etnología de Cataluña, que se hizo efectiva a inicios de 2008, y la propuesta de un museo nacional que integraría los actuales museos de etnología, historia y de arqueología.

El proyecto de este nuevo museo de sociedad, en consonancia con las líneas museológicas de otros países (por ejemplo el Musée de la Civilisation de Québec, el MUCEM de Marsella, el National Museum of Scotland o el Musée des Confluences de Lyon, entre tantos otros) ponía sobre la mesa el interesante debate sobre el futuro de los museos etnológicos y la necesidad de romper las fronteras disciplinarias, sino también los temas clásicos de la antropología, potenciando alianzas con otras disciplinas para una mejor difusión de los temas museológicos y haciendo posible una verdadera renovación museológica. Se justificaba igualmente por motivos económicos y técnicos, pero también para intentar conseguir un museo suficientemente atractivo y emblemático (Roigé y Arrieta, 2010:545). En la presentación, el Consejero de Cultura de ese momento lo calificó como "un museo muy ambicioso, que tratará sobre la memoria de las sociedades, sobre la memoria histórica, pero también debe presentar la sociedad del presente y del futuro, con nuevas tecnologías, debe ser un centro de referencia internacional, un museo de la era de la globalización, del siglo XXI para las nuevas generaciones"10. Por ello, el museo no sólo partiría del "conocimiento de las ciencias sociales, potenciando el discurso transversal, desde múltiples miradas. No sólo nos hablaría de las formas de vida, de los acontecimientos $y$ de la evolución cultural producida a lo largo del tiempo en el territorio que hoy conocemos como Cataluña, sino que también presentaría grandes temas de actualidad"11.

10. Vilaweb, "Pla de museus de Catalunya, un pla postnoucentista", 21/1/2008. http://www. vilaweb.cat [consulta: 16/8/2009]

11. Se han ido presentado distintos Planes de Museos por parte de la Generalitat de Catalunya. Después de la LLei de Museus (1990), que marcaba el panorama museístico catalán, se elaboró en el 2007 un Pla de museus de Catalunya; que fue actualizado en el 2012 con las Bases per a un Nou Pla de Museus de Catalunya, y más recientemente en julio de 2015 con un Document de treball per a un Nou Pla de Museus de Catalunya. Sistema de Museus de Catalunya. http://cultura.gencat.cat/ca/departament/estructura_i_ adreces/organismes/dgpc/temes/museus/el_sistema_de_museus_de_catalunya/ [Consulta:31-8-2015]. 
La propuesta suscitó interesantes polémicas, sobre todo en dos aspectos: la conveniencia de la integración del museo de arqueología en un proyecto común; y en cómo tratar la identidad y la sociedad catalana y su diversidad cultural. La primera fue la que motivó más críticas, reclamándose la continuidad del Museo de Arqueología por su larga tradición histórica y por la importancia de la disciplina. Resulta paradójico, en este sentido, que mientras que el colectivo de arqueólogos catalanes inició una fuerte campaña en defensa de su museo, entre los profesionales de la antropología la propuesta de un museo etnológico prácticamente no suscitó ninguna defensa. En el 2008, poco después de la publicación del nuevo Plan de Museos, y a pesar de que éste definía muy poco el proyecto del futuro Museo unificado, se impulsó un manifiesto, firmado por más de 1.300 personas (entre ellos un buen número de arqueólogos y profesores de universidad). El manifiesto aludía al pasado del museo como necesario en un país "normal" ${ }^{2}$. Otras críticas, aun mostrando el acuerdo con la creación de un museo de ciencias sociales, discrepaban en la configuración de este museo e insistían únicamente en cuestiones de carácter museológico y científico, opinando que debían integrarse en este museo el de Historia, el de Etnología y el de Ciencia y la Técnica, respetando "los dos buques insignias que nos dejaron como legado nuestros antepasados aún tan cercanos: el Museo de Arte y el Museo de Arqueología" (Prats, 2007: 175).

Los debates sobre cómo mostrar la identidad fueron importantes, aunque de menor intensidad ${ }^{13}$. El proyecto ampliaba el Museu d'Història de Catalunya, creado para divulgar la identidad catalana y aunque se hablaba poco de la idea de identidad en el texto del proyecto, el propio Director General de Patrimonio, en su comparecencia parlamentaria, lo calificaba como un museo "que nos sirva para hablar del pasado, para hablar del presente y para hablar del futuro. Queremos que sea un museo que nos sirva como herramienta integradora de los nuevos colectivos que viven en Cataluña"14. Se trataba, en cierta manera, de crear un "museo posnacional" (Alcalde, Boya y Roigé, 2011), de una forma distinta de hablar de un nuevo modelo de identidad, de forma muy similar a las que han surgido en proyectos parecidos en otros países. Como en estos museos, el proyecto era de carácter interdisciplinario, basado en exposiciones temporales más que permanentes (superando las dificultades de abordar una síntesis que caiga en el reduccionismo) y en una reformulación del tema de las identidades en una visión más genérica y no lineal, mostrando cómo los contactos, las tradiciones, y los cambios

12. "S.O.S. Museu d'Arqueologia de Catalunya", 2008. www.petitiononline.com/sosmac/ [consulta: $30 / 3 / 2010]$

13. "Gestación del museo Catalonia”. El País, 22 de enero 2008. http://elpais.com/diario/2008/01/22/ catalunya/1200967665_850215.html.

14. “Compareixença de Josep Maria Carreté i Nadal, director general del Patrimoni Cultural”, Diari de Sessions del Parlament de Catalunya, 9 de julio de 2008, Serie C, n. 362, p. 24. 
se traducen en la construcción de nuevas identidades en el contexto de una sociedad globalizada.

Teniendo en cuenta el fuerte carácter identitario de este tipo de museos, parece extraño que no se haya creado un museo etnológico dedicado a presentar y explicar la identidad catalana. Las razones son diversas, pero a nuestro entender podemos considerar tres factores explicativos: el escaso interés de la disciplina antropológica catalana por la museología (la falta de presión del colectivo, mientras que en otros casos como el de Arqueología sí han reivindicado fuertemente la existencia de un museo específico); las dificultades explicativas de la identidad en un museo; y el hecho de que el proyecto de identidad catalana no se haya centrado tanto en el patrimonio como en otros conceptos de identidad. La crisis ha acabado de afectar al proyecto, hasta el punto de que en el último Plan de Museos presentado (julio 2015) ya ni tan sólo se menciona la existencia de un Museo Nacional de Etnología y sí el mantenimiento de un Museo de Historia y Sociedad. Que el gobierno opte por mantener un museo de historia o un museo de arqueología es ciertamente una opción defendible políticamente e incluso académicamente. Pero el olvido de un museo de sociedad significa la desaparición de un interesante proyecto que no jugaría el mismo rol que un museo de historia.

\section{LOS MUSEOS SOBRE “OTRAS CULTURAS”}

Otra paradoja de los museos etnológicos catalanes, es el escaso desarrollo de los museos dedicados a otras culturas. A excepción del Museu Etnològic de Barcelona (actualmente en proceso de renovación), del recientemente abierto como Museu de les Cultures del Món, y de algunas pequeñas colecciones como el Museu Etnogràfic Índio-Amazonic dels Caputxins de Sarrià ${ }^{15}$, son muy pocos los museos que tratan de otras culturas.

El escaso desarrollo de estos museos, de forma similar a lo que ocurre en todo el Estado Español (Ortíz, 1995), se debe en gran parte al hecho de que España fuese una potencia colonial en declive en el momento del desarrollo de los grandes museos etnológicos a fines del XIX, y al escaso desarrollo de la disciplina antropológica hasta los años 1970 (Romero de Tejada, 2004). Es sintomático, en el mismo sentido, que no existan tampoco muchos proyectos de museos que fomenten el diálogo intercultural, cuando es uno de los temas que más preocupa a la sociedad catalana.

Durante muchos años, el Museu Etnològic de Barcelona, al cual ya nos hemos referido, cumplió en solitario esta misión. Durante la primera década del 2000, el museo inició una nueva línea de exposición estable, que trataba desde las culturas tradicionales a la interculturalidad, y de comunicación abierta en un espacio de diálogo y de reconocimiento

15. Este museo actualmente sólo es visitable mediante horas concertadas. Su creación está relacionada con las tareas misionales, ya desde principios del siglo XX (de Manresa, 1997). 
entre culturas. Se prestó especial atención al mundo obrero industrial catalán y de otras comunidades o grupos sociales como los gitanos, los judíos, los americanos o los africanos, y se realizaron numerosas actividades relacionadas con diversos colectivos en el contexto de unos años de fuerte inmigración. A pesar de su buena orientación y programa, la falta de medios, un escaso interés político por parte de las autoridades municipales y catalanas, y su ubicación bastante inaccesible, determinaron un impacto reducido. Así y todo, en el 2011, el museo se cerraba con el objetivo de una profunda reforma del edificio y con la idea de mejorar considerablemente su exposición.

El proyecto, no obstante, se modificó porque el nuevo Ayuntamiento elegido en el 2010 planteó la creación de un nuevo Museo de las Culturas del Mundo (2015), que acogió las piezas de mayor valor del MEB. En el 2012, el Museo de Arte Precolombino Barbier Muller cerró las puertas por falta de acuerdo entre el propietario de la colección y el Ayuntamiento sobre la adquisición de la colección, que estaba prestada a la ciudad desde $1997^{16}$. El cierre dejó un espacio vacío, justo delante del Museu Picasso y en una de las zonas más turísticas de la ciudad, por lo que se decidió aprovechar ese espacio para acoger parte de la colección del Etnológico y la colección particular Folch cedida a la ciudad por un período de veinte años.

A inspiración de otros museos que exponen los objetos etnológicos como obras de arte, el proyecto museológico se hizo en base a un diseño aséptico y ordenando la colección por continentes, países, religiones o zonas culturales, sin tener en cuenta la funcionalidad de los objetos. El museo expone las colecciones para su contemplación estética, con piezas aisladas de las condiciones materiales, sociales e históricas en que fueron producidas, con pocas alusiones al colonialismo y poscolialismo y a una concepción amplia de la cultura. Muchas de las críticas vertidas al Museo Quai Branly son aplicables en este caso (Price, 2007), con el agravante de que se trata de una colección mucho más reducida y con menor contenido narrativo. Se perdió la oportunidad de crear un museo moderno, de reflexión multicultural en la línea de los que se denominan precisamente como museos de culturas del mundo, como el Tropenmuseum de Ámsterdam, el de las Culturas del Mundo de Goteborg o Colonia (Van Geert, 2014). Más que un museo dedicado al diálogo intercultural, se basa en unos criterios de selección estética de los objetos, planteándose como un museo que pretende "la preservación, la presentación y la difusión del patrimonio

16.. El Museu Barbier Muller se inauguró en 1997 gracias a un préstamo inicial de 5 años que hizo el museo suizo al Ayuntamiento de Barcelona, cerrando sus puertas por un desacuerdo entre el Ayuntamiento y el propietario de la colección en cuanto a la renovación del préstamo. Se planteó la posibilidad de realizar el préstamo de otra colección al museo, en concreto la africana, pero el Ayuntamiento y el propietario no se pusieron de acuerdo, por lo que se acordó el cierre definitivo del museo, y su substitución por el Museo de las Culturas del Mundo. La colección fue vendida en París en subasta (en Sotheby's), a pesar de la reclamación de las autoridades del Perú de restituir 60 piezas de arqueología colomina de las 313 del catálogo (Crochet, 2013). La colección, adquirida desde 1920, estuvo expuesta en el Hermitage y en Lausanna antes de su préstamo a la ciudad de Barcelona en 1997. 
artístico y cultural de diferentes culturas de África, Asia, América y Oceanía. Muestra la diversidad cultural a través de la experiencia artística de los pueblos desde una perspectiva pluridisciplinaria y su voluntad es convertirse en una plataforma de difusión y proyección social del patrimonio y el conocimiento de otras culturas del mundo"17. El proyecto parte de una visión artística del objeto etnológico sin considerar el papel del colonialismo hacia estos continentes ni el contexto cultural de producción de estas obras. Ante las críticas, los responsables del museo argumentaron que se trata esencialmente de un museo de arte. Como explicó el comisario y director de Cultura del Ayuntamiento en ese momento "queremos reconocer que hay arte, y que siempre ha habido arte en Asia, América, Oceanía y África, que no hay artes con niveles diferentes, sino que el arte es un concepto universal de la humanidad", mientras que el teniente de alcalde de Cultura, Jaume Ciurana sostenía que "es un museo de arte pero que tiene un interés especial en colocar las piezas de arte en su contexto histórico, geográfico, social y simbólico"18.

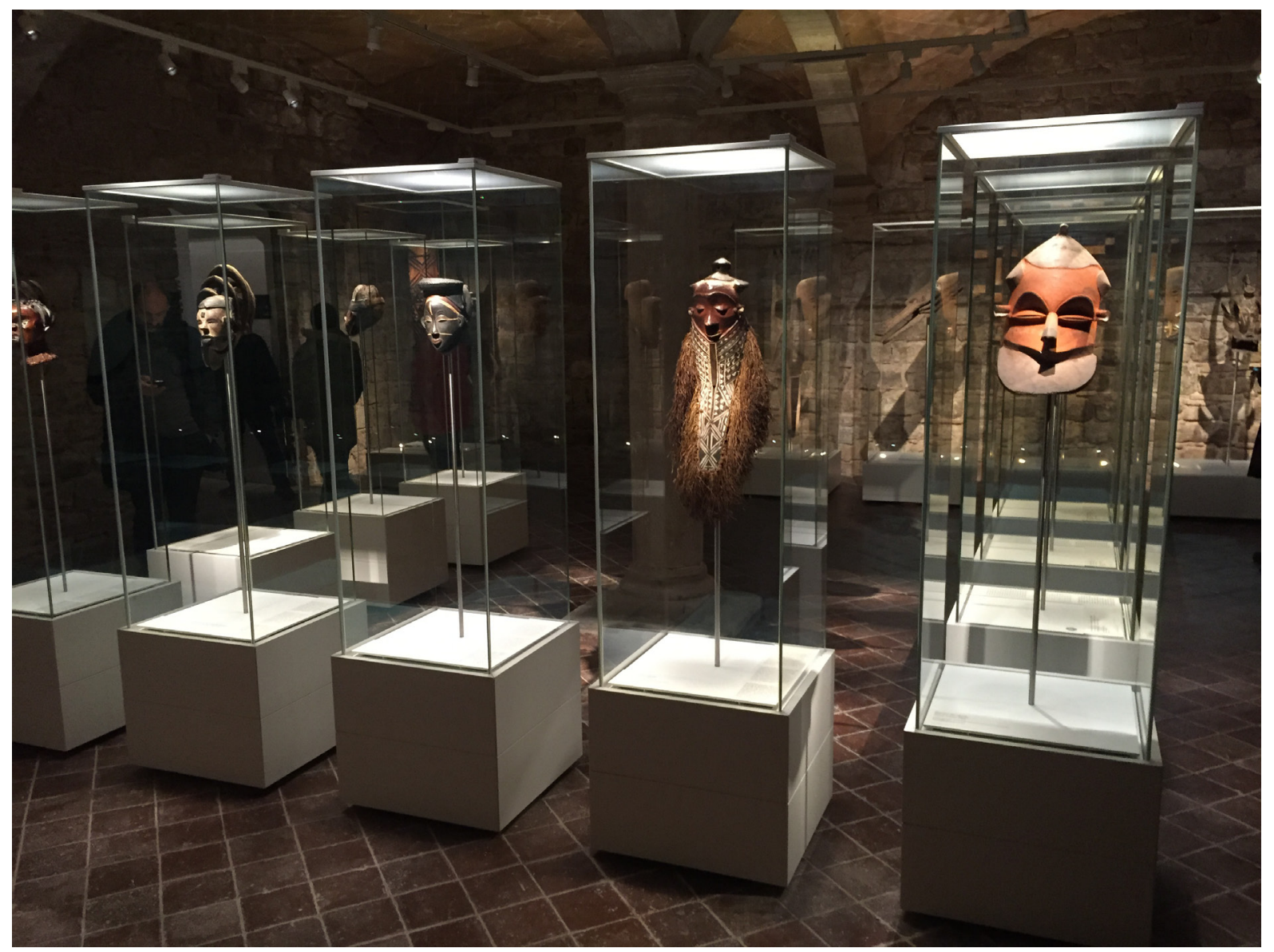

Foto 6: Museu de les Cultures del Món, Barcelona. Un nuevo museo donde predomina la presentación estética del patrimonio etnológico. (Foto: Xavier Roigé)

17. "Museu de les cultures del món", Ara, 4-2-2015. http://www.ara.cat/barcelona/Museu-cultures-delmon_0_1297670469.html

18. "Museu de les cultures del món", Ara, 4-2-2015. http://www.ara.cat/barcelona/Museu-cultures-delmon_0_1297670469.html 
Pero así y todo las autoridades pretendían señalar el carácter de diálogo cultural del museo. Para el alcalde de Barcelona en ese momento, Xavier Trias, "el Museo de Culturas del Mundo se enmarca en la clara voluntad de relacionar Barcelona con los otros continentes $y$ culturas lejanas, porque esta ciudad ha sido siempre, y lo sigue siendo, una ciudad de acogida, que dialoga y que está abierta a las aportaciones e influencias culturales más diversas" 19 . Su apertura desencadenó un buen número de críticas, destacando un manifiesto titulado "Barcelona y los museos como pesebres" y suscrito por 80 profesionales de la antropología en el que tildaban el nuevo museo de reduccionista al "pretender esencialmente rescatar la visión estética de los objetos pertenecientes a otras sociedades, reproduciendo la vieja consigna de que el acto de contemplación debe ser independiente de las condiciones de su producción y apropiación para evitar tal vez que informaciones inoportunas contaminen el juicio puro y sensible de los espectadores" ${ }^{20}$. El Museo, por otra parte, no ha conseguido tampoco un éxito de público, como podía intuirse por su ubicación y por su proyecto, que preveía unos 300.000 visitantes anuales. A pesar de que durante sus dos primeros meses de apertura (febrero y marzo de 2015), con entrada gratuita, consiguió 50.208 visitantes $^{21}$, desde entonces su número ha ido decreciendo, hasta el punto de que el número de visitantes actual es muy reducido ${ }^{22}$. Son cifras muy alejadas de las expectativas iniciales del museo, teniendo en cuenta su inversión y su céntrica ubicación, pero en este momento cualquier análisis resulta prematuro. Deberá esperarse uno o más años para conocer las tendencias de público y ver cómo los nuevos gestores del museo realizan una programación de actividades y exposiciones suficientemente atractiva.

En cuanto al Museo Etnológico, después de varios años cerrado por reformas, su reapertura está prevista también para octubre de 2015, con los espacios renovados y una nueva museografía. El museo, se configurará con piezas de etnografía catalana en su mayoría, pero no exclusivamente, y tomará los objetos de la vida cotidiana como eje vertebrador. Abrirá sus puertas tras cuatro años de obras y una inversión superior a los tres millones. Según su director, el museo será "un ejemplo de museología social", entendiendo "el museo no como un lugar donde se exponen piezas que la ciudadanía

19. "Museu de les cultures del món", Ara, 4-2-2015. http://www.ara.cat/barcelona/Museu-cultures-delmon_0_1297670469.html

20. GRECS, "Els museus com a pesebres", http://observatoriconflicteurba.org/2014/12/15/barcelona-iels-museus-com-a-pessebres/

21. "Més de 50.000 persones han visitat ja el Museu de Cultures del Món”, ACN, 8-4-2015. http://www. acn.cat/acn/784924/Noticia/text/Noticia.html

22. "En mitad del Born y solo 160 visitas al día”, El Periódico, 24 de agosto de 2015. http://www.elperiodico. com/es/noticias/barcelona/mitad-del-born-solo-160-visitas-dia-4450297. "El museo estrella de Trias no tiene visitantes”, 02B, 17 de mayo de 2015, http://www.02b.com/es/notices/2015/05/el-museo-estrellade-xavier-trias-no-tiene-visitantes-12706.php 
contempla, sino como un espacio donde podemos reflexionar sobre nosotros mismos". Para comenzar, el Etnológico presentará dos exposiciones: "Lo sagrado, lo profano y la fiesta", que hace un recorrido sobre el ciclo festivo anual, sobre los orígenes religiosos y las expresiones contemporáneas de las fiestas, y "Tierra de alfareros", en torno a la cultura del agua y los oficios que se relacionan en el marco del Mediterráneo ${ }^{23}$.

\section{RETOS Y DEBATES PARA EL FUTURO}

De la evolución de los museos etnológicos en Cataluña, de su situación y de los debates que hemos presentado se abren diversos interrogantes acerca del futuro de los museos etnológicos. Son muchos los retos que los museos etnológicos deberán sortear, pero sinteticémoslos en cuatro.

1) Sin duda, la financiación es el reto más difícil. La cuestión es compleja porque está ahogando las posibilidades de funcionamiento cotidiano, las condiciones laborales y las posibilidades derenovación, y está comportando un cambio de los modelos definanciación y objetivos de los museos. Pero como señala Bergeron (2009:66), la crisis también está obligando a los museos a replantearse su misión, el desarrollo de sus colecciones y sus estrategias de comunicación. Y como también sugiere este autor (2012:80), debemos ser optimistas porque a pesar de que la financiación de los museos por parte de los distintos organismos gubernamentales parece, más que nunca, amenazada, debemos convencer a esos organismos de la necesidad de que los museos perduren por su papel cultural y social, por su contribución a los grandes aspectos de una cultura compartida, abierta, en una sociedad informada. Si los museos etnológicos consiguen readaptar sus discursos, serán capaces de ofrecer muchas respuestas a los grandes retos de la sociedad contemporánea. Es cierto que los políticos esperan que los recursos propios, más allá de los aportados por las instituciones públicas, sean cada vez más importantes con el objetivo de aliviar las responsabilidades de los gobiernos, y que ello condicionará la evolución de los museos. Pero así y todo los museos etnológicos deberán ser capaces de convencer a las autoridades que la inversión en museos puede ser útil en períodos de crisis, porque los museos pueden contribuir a la estabilidad social. Parafraseando a la obra del economista Schumacher (Small is beuatiful), Bergeron (2012:82) considera la necesidad de tener en cuenta en los museos las acciones a escala humana considerando la economía desde el punto de vista del desarrollo sostenible. El arraigo de estos museos no se basa en una lógica económica, sino en una lógica comunitaria y social, por lo que los pequeños museos tienen un papel importante en la economía regional.

23. "El Museu Etnològic reobrirà les portes el 4 d’octubre", Nació digital, 6 de julio de 2015. http://www. naciodigital.cat/noticia/90484/museu/etnologic/reobrira/portes/octubre. 
2) Pero más allá de los retos financieros -que amenzan la continuidad de los museos o les obligan a reformularse- los museos etnológicos catalanes tienen ante sí otros retos no menos complejos. La fiebre de museos que ha comportado la creación de un gran número de museos obligará a una reorganización de difícil digestión. No se trata tanto de cerrar museos como de rentabilizar recursos, de trabajar en redes realmente eficaces para las cuestiones técnicas, de compartir personal y de superar el aislamiento local. Ello parece simple, pero es sumamente complejo.

3) No cabe duda de que los museos se encuentran actualmente en un período de grandes mutaciones. La noción de patrimonio se ha convertido en polisémica y las nuevas formas de patrimonio se han multiplicado. Por una parte, están proliferando otros tipos de patrimonio al margen de los museos, como el patrimonio inmaterial, cada vez más importante. En cierta manera los museos están dejando de tener la exclusividad de la gestión del patrimonio. Por otra parte, los objetos -aunque continuarán teniendo su rol importante- dejarán de tener el rol preponderante. Las nuevas reservas son cada vez más digitales y la noción de autenticidad no tiene hoy en día el mismo significado que tuvo hace unas décadas (Bergeron, 2012:84). La creación de museos digitales es una asignatura pendiente de los museos, en una cultura en que el libro, la prensa o la música ya circulan predominantemente por internet y las redes sociales. Las nuevas tecnologías -aún poco utilizadas- permitirán a los museos la creación de nuevas formas de difusión de sus colecciones y exposiciones.

4) Otro gran reto de la museología etnológica catalana es la creación de un museo nacional de etnología. La riqueza de los museos locales cumple bien su misión, pero falta un organismo que sea capaz de dirigir y coordinar sus esfuerzos, y sobre todo de prestigiar el rol de los museos antropológicos. Ni la crisis económica, ni los intereses sociales ni políticos parecen ayudar en este objetivo, que como hemos visto no ha pasado de declaraciones de intenciones.

5) Más allá de la financiación, los rápidos cambios sociales que experimenta la sociedad catalana están incidiendo también en los museos etnológicos, muchos de los cuales son producto o herencia teórica de la renovación museológica de los ochenta. Sin abandonar los temas clásicos, es necesaria la incorporación de temas actuales (como la inmigración, la diversidad cultural, las relaciones entre culturas, los nacionalismos, los conflictos, las transformaciones familiares, el turismo, los espacios urbanos o los nuevos rituales, las reflexiones sobre los movimientos de reivindicación independentistas y los nuevos movimientos sociales, por citar sólo algunos ejemplos). El Museu de la Immigració de Catalunya, en Sant Adrià del Besòs, es un buen ejemplo de nuevas líneas a seguir. La ventaja del patrimonio etnológico frente a otras formas de patrimonio consiste en que 
puede tratar de temas contemporáneos que están en el centro de las preocupaciones sociales. Lógicamente, estos temas son en muchos casos conflictivos y generan debates sociales, pero resultan imprescindibles para la expansión futura de los museos etnológicos.

Foto 7: "El Sevillano". El tren que unía Sevilla y Barcelona, y que durante muchos años fue el nexo de llegada de un gran número de andaluces a Cataluña, es el elemento explicativo principal del Museu de la Immigració, Sant Adrià del Besòs. (Foto: Xavier Roigé)

Los retos son enormes. ¿Cómo llegar a los nuevos movimientos sociales surgidos de la crisis? La crisis, como es conocido, ha implicado la creación de reivindicaciones sociales como la vivienda, el multiculturalismo, el paro o los movimientos soberanistas en Cataluña. ¿Podrán los museos hacerse cómplices o atraer a estos movimientos? ¿Están preparados para tratar estos temas y convertirse en un lugar de debate social? Los museos etnológicos, por las temáticas que tratan, deberían fijar estas cuestiones como prioritarias, pero hasta el momento estas cuestiones se plantean sólo como declaración de principios. Sometidos a una fuerte presión por la exigencia de conseguir nuevos recursos, los museos deben participar de forma importante en un proceso que trate de combinar el valor social y económico del patrimonio. 


\section{BIBLIOGRAFÍA}

ALCALDE, Gabriel; BOYA, Jusèp y ROIGÉ, Xavier (2011). Museums of Today: The New Museums of Society. Girona: Documenta Universitaria.

ALCALDE, Gabriel y RUEDA, Manuel (2012) "Ecomuseology and local museums in Catalonia (Spain). Influences and coincidences during the 1975-1985 period”. En S. Lira, R. Amôeda, C. Pinhero, P. Davis, M. Stefano y G. Corsane (eds.) Ecomuseums 2012. Barcelos: Green Lines Institute, pp.1-8.

ANDREU, Agustí (2007) “Más allá del museo. Las actividades económicas del patrimonio: de los parques naturales a las fiestas temáticas". En I. Arrieta (ed.) Patrimonios culturales y museos. Bilbao, pp. 61-88

BERGERON, Yves (2009) "Los museos y la crisis.Tendencias en los museos norteamericanos". Museos.es, 3, pp. 59-67.

BERGERON, Yves (2014) "Les liaisons dangereuses ou les relations troubles entre le politique et les musées canadiens". THEMA. La revue des Musées de la civilisation, 1, pp. 127-153.

CROCHET, Alexandre (2013) "La collection Barbier-Mueller, une vente test". Le Quotidien de l'Art, 18 de marzo de 2013, http://lequotidiendelart.com/quotidien_articles_detail. php?idarticle $=2235$

DAVALLON, Jean (2002) "Les objets ethnologiques peuvent-ils devenir des objets de patrimoine?". En M-O. Gonseth, J. Hainard y R. Kaehr (dirs.) Le musée canibale. Neuchatel: Musée d'Ethnographie, pp. 169-187.

DESVALLÉES, André (1995) “Les musées d’ethnographie ont-ils encore un sens?”. Anales del Museo Nacional de Antropología, 1, pp. 51-84.

DESVALLÉES, André y MAIRESSE, François (2002) L'écomusée: rêve ou réalité Lyon: Presses Universitaires.

FERNÁNDEZ DE PAZ, Esther (2008) “El futuro Museo Nacional de Etnografía. Una balanza descompensada entre ciencia y política”. En X. Roigé, E. Fernández de Paz e I. Arrieta (coords.) El futuro de los museos etnológicos. San Sebastián: Ankulegi Antropologia Elkartea, pp. 147-162.

GENIOLA, Andrea (2014) "El nacionalismo regionalizado y la región franquista: dogma universal, particularismo espiritual, erudición folklorica (1939-1959)". En F. Archiles, e I. Sanz (coords.) Naciones y estado: la cuestión española. Valencia: Universitat de València, pp. 189-224.

GOB, André (2007) Des musées au-dessus de tout soupçon. Paris: Armand Colin.

GREFFE, Xavier (2003) La valorisation économique du patrimoine. Paris: Gallimard. 
INIESTA, Montserrat (1994) Els gabinets del món. Antropologia, museus i museologies. Lleida: Pagès.

JEAN, Yves (1997) "Analyse comparative des deux modèles explicatifs des évolutions des espaces ruraux français”. Annales de Géographie, 106 (59), pp. 631-646.

JUAN I NEBOT, Antònia (1998) "Ramon Violant, etnògraf, entre el Museu de Ripoll i el del Poble Espanyol”. Revista de Girona, 186, pp. 46-52.

MAZÉ, Camille; POULARD, Frédéric y VENTURA, Christelle, Dirs. (2013) Les Musées d'ethnologie. Culture, politique et changement institutionnel. Paris: Éditions du Comité des Travaux Historiques et Scientifique.

MOUTINHO, Mario (1986) "Mouvement international pour une nouvelle muséologie", L'Homme, 26, pp. 129-129.

MONTAÑÉS, José Ángel (2012) “Museus com bolets", El País, 13 de diciembre de 2012, http://ccaa.elpais.com/ccaa/2012/12/12/quadern/1355349226_411885.html

ORTÍZ, Carmen (1995) "Els museus d'ultramar i colonials a Espanya. Revista deetnologia de Catalunya, 7, pp. 20-29.

ORTÍZ, Carmen (1997) "Folklore y franquismo". En R. Huertas y C. Ortiz (eds.) Ciencia y fascismo. Madrid: Ediciones Doce Calles, pp. 161-180.

POMIAN, Krzysztof (1990) "Musée et patrimoine". En H-P. Jeudy (ed.) Patrimoines en folie. París: Éditions de la MSH, pp. 177-198.

PRATS, Llorenç (1995) “Què és el patrimoni etnològic?”. En L. Calvo y J. Mañà (eds.) De l'ahir i de l'avui. El patrimoni etnologic de Catalunya. Barcelona: Generalitat de Catalunya, pp. 18-25.

PRATS, Llorenç (2007) "La gestió del Patrimoni Etnològic en el Pla de Museus de Catalunya (2007-2010)”. Mnemòsine: Revista catalana de museologia, 4, pp. 167-175.

PRATS, Llorenç (2014) "El caràcter magmàtic del patrimoni etnològic". Revista d'Etnologia de Catalunya, 39, pp. 152-159.

PRICE, Sally (2007) Paris primitive: Jacques Chirac's museum on the Quai Branly. Chicago: University of Chicago Press.

RASSE, Paul (2000) "Processus de mondialisation et mediation des identites locales". En M. Gelarau (ed.) Médiation des cultures. Lille: Presses Universitaires, pp. 39-50.

RIVIÈRE, Georges Henri, y otros (1989) La muséologie selon Georges Henri Rivière: cours de muséologie: textes et témoignages. París: Dunod.

ROIGÉ, Xavier (2014) "Los Museos de la Ciencia en España: entre la Divulgación Científica, el Consumo Cultural y la Creación de Nuevos Referentes Sociales". The Journal of Deliberative Mechanisms in Science, 3 (1). 
ROIGÉ, Xavier y ARRIETA, Iñaki (2010) “Construcción de identidades en los museos de Cataluña y el País Vasco: entre lo local, nacional y global”. Pasos. Revista de Turismo y Patrimonio Cultural, 8 (8), pp. 539-555.

ROIGÉ, Xavier y Arrieta, Iñaki (2014) “ ¿Una sociedad congelada?: la representación de la sociedad rural en los museos". Arxius de Sociología, 30, pp.73-86.

ROIGÉ, Xavier; ARRIETA, Iñaki y ABELLA, Jordi (2012) "The development of ecomuseums in Spain. Between crisis and redefinition". En S. Lira, R. Amôeda, C. Pinhero, P. Davis, M. Stefano y G. Corsane (dirs.) Ecomuseums 2012. Barcelos: Grren Lines Institute, pp. 351-360.

ROIGÉ, Xavier y FRIGOLÉ, Joan, Eds. (2010) Constructing Cultural and Natural Heritage. Parks, Museums and Rural Heritage. Girona: Documenta.

ROMERO DE TEJADA, Pilar (2004) "Las exposiciones temporales en el Museo Nacional de Antropología”. Anales del Museo Nacional de Antropología, 10, pp. 193-210.

RUEDA, Josep Manuel (1992) “El Museu Etnològic del Montseny”. Revista d'Etnologia de Catalunya, 1, pp. 115-119.

RUEDA, Josep Manuel (2007) “Els orígens i evolució dels museus etnogràfics a Catalunya”. Mnemòsine. Revista Catalana de Museologia, 4, pp. 121-139.

SERRA DE MANRESA, Fra Valentí (1997) “Aproximació històrica al Museu Etnogràfic Andinoamazònic dels Caputxins de Catalunya". Revista d'Etnologia de Catalunya, 10, pp.148-149.

SERRA, Maria de LLuc (2010) "Etnologia i museologia: els museus etnològics als anys quaranta”. Revista d'Etnologia de Catalunya, 37, pp.142-144.

VAN GEERT, Fabien (2014) Du musée colonial au musée des diversités. Intégrations et effets du multiculturalisme sur les musées ethnologiques. Barcelona: Universitat de Barcelona, Tesis Doctoral. http://hdl.handle.net/10803/286827

VENTOSA, Sílvia (1994) "El rol dels museus etnogràfics en la societat actual”. Revista d'Etnologia de Catalunya, 6, pp. 54-61. 